\title{
TEACHING ENQUIRY WITH MYSTERIES INCORPORATED: THE BENEFITS OF INVOLVING PRE-SERVICE TEACHERS
}

\author{
Beulah McManus ${ }^{1,3}$, Anne O’Dwyer, ${ }^{1}$ Peter Childs, ${ }^{1,2}$ Joanne Broggy, ${ }^{1,3}$ \\ Orla McCormack ${ }^{3}$ \\ ${ }^{1}$ National Centre for STEM Education, \\ 2Department of Chemical and Environmental Sciences, \\ 3Department of Education and Professional Studies, University of Limerick, Limerick, Ireland.
}

\begin{abstract}
TEMI, Teaching Enquiry with Mysteries Incorporated, is an EU-funded FP7 Science in Society project running from 2013 to 2016. The project aims to encourage science teachers to develop an understanding of inquiry-based learning as well as developing an understanding of the benefits of utilising such approaches in one's classroom. Drawing on the 5E learning cycle, TEMI aims to engage pupils in core scientific concepts through the integration of mysteries and discrepant events in science lessons. This current discussion paper explores the approaches taken by the UL project team, one of the partners in the project, to bring about change in Irish second-level science teaching, as part of the TEMI project. In particular, it focuses on the unique aspect of this institution's approach, which is the involvement of pre-service science teachers (PSST's) in the project. The role of PSSTs in the project is explored under three main headings: "TEMI and the PSST as researcher", "TEMI and professional learning communities" and "TEMI and PSST's collaboration with co-operating teachers". The paper concludes with a discussion on the benefits of involving PSSTs in the TEMI project.
\end{abstract}

\section{Introduction}

Within post-primary education in Ireland there is a preoccupation with coverage of course material and preparation for final examinations (Gleeson, 2010). The terminal state examination dominates teaching and learning, influencing such aspects as pedagogy, student-teacher relationships, resources, time allocations and approaches to assessment (see for example Callan, 1995 and Gleeson, 2010 for further discussion on teaching, learning and assessment in Irish post-primary schools). Consequently, getting the grade and meeting the examiner's expectations become the most important aspect of education, and consequently a number of important activities and innovative teaching approaches "are ignored because the system places undue pressure and stress on students [and there is] a narrowing of the curriculum arising from the tendency to teach to the examination results and an undue focus on the attainment of results" (Government of Ireland, 1998, p.108). Within such a context, it can be difficult for teachers, irrespective of their knowledge and interest in other areas of education or alternative pedagogical approaches, to stop focusing on the direct transmission of knowledge and teaching towards the examination (McCormack \& O’Flaherty, 2010).

A recent study, conducted by the Organisation of Economic Co-operation and Development (OECD, 2009), found that Irish teachers valued direct transmission teaching 
approaches more than teachers in other OECD countries (e.g. Poland, Austria and Denmark). Irish teachers were less likely to hold constructivist beliefs on teaching and learning than their European counterparts (ibid, 2009).

However, the context is changing. The Department of Education and Skills (DES, 2012), drawing on work by the National Council for Curriculum and Assessment (NCCA, 2011), have proposed changes to lower post-primary schooling that would see emphasis shift from summative assessment to more student-centred pedagogical approaches and greater use of formative assessment. Furthermore, proposed changes to Junior and Senior Cycle Science aim to introduce a new and increased focus on teaching through enquiry ${ }^{1}$ (NCCA, 2013).

TEMI, Teaching Enquiry with Mysteries Incorporated, is an EU-funded FP7 Science in Society project running from 2013 to 2016. The project aims to encourage in-service science teachers (ISSTs) to develop an understanding of inquiry-based learning (IBL) as well as developing an understanding of the benefits of utilising such approaches in one's classroom. The TEMI project is attempting to promote inquiry-based teaching in postprimary schools, in order to help young students across Europe develop a passion for science. The project is coordinated by Queen Mary University of London, with 13 partners from 11 countries (see Appendix 1 for full list), including the authors' institution at the University of Limerick (UL), Ireland.

This current discussion paper explores the approaches taken by the UL project team to bring about change in Irish second-level science teaching, as part of the TEMI project. In particular, it focuses on the unique aspect of this institution's approach, which was the involvement of pre-service science teachers (PSST's) in the project. While in-service science teachers (ISST's) were the main focus of the project, the authors would argue that the engagement of PSST's and the ways in which they were engaged in the project is fundamental to introducing inquiry-based learning into Irish classrooms.

The TEMI project is firstly introduced in more detail with particular emphasis placed on the engagement of PSST's in three key areas: "TEMI and the PSST as researcher", "TEMI and professional learning communities" and "TEMI and PSST's collaboration with co-operating teachers". The paper concludes with a discussion on the benefits of involving pre-service teachers in the TEMI project.

\section{The TEMI project - Teaching enquiry with mysteries incorporated}

The aim of the $3 \frac{1}{2}$-year TEMI project is to help transform science and mathematics teachers' pedagogical practices across Europe by encouraging teachers to develop new skills to engage pupils in the learning process. The provision of new teaching and learning

\footnotetext{
${ }^{1}$ Enquiry and Inquiry both appear in the related research literature. For the purposes of this paper (and in the TE

MI project, enquiry is used, with the exception in reference to the terms IBSE (Inquiry Based Science Education) and IBL (Inquiry Based Learning)
} 
resources and supporting teaches in introducing enquiry-based lessons into their teaching are central facets of the project. Innovative "Enquiry Labs" and workshops are being developed by the participating teacher education institutions and teacher networks across Europe, which are based around the core scientific concepts of solving mysteries and exploring discrepant events i.e. an event that goes against one's preconceived ideas of what should/ would happen. (Liem, 1990)

There are many EU FP7 funded Inquiry Based Science Education (IBSE) projects running in Europe, which focus on second level teachers and pupils. So how is TEMI unique? The TEMI project is based on four innovations, which it aims to embed in science teachers' practice, through the provision of continuing professional development (CPD) workshops. These four innovations are:

- Create curiosity through the use of mysteries or discrepant events.

- Teach concepts with the 5E learning cycle (focusing on Engage, Explore, Explain, Elaborate and Evaluate ${ }^{2}$ )

- Teach skills with Gradual Release of Responsibility.

- Maintain motivation with Showmanship.

A mystery is a phenomenon or event that provokes the perception of suspense and wonder in the learner, in order to initiate an emotionally-laden "want to know" feeling, which leads to an increase in curiosity. This in turn encourages the pupils to start asking questions, which they try to answer by inquiry-based and problem-solving activities (TEMI, 2013). Such mysteries, which have a scientific basis and explanation, are also known in the science education literature as discrepant events. There is a massive literature describing discrepant events and their role in science education (e.g. Liem, 1990; McCormack, 1990; O’Brien, 2010). The various project partners are tasked with developing lessons around such scientific mysteries, and introducing them to practising (and if desired pre-service) science teachers, who will implement them in their classrooms and evaluate their effectiveness in engaging their pupils. These lesson ideas will also be shared on a central portal and translated into national languages.

\subsection{The TEMI approach and inquiry}

Inquiry Based Science Education (IBSE) has been adopted worldwide in the 21 $1^{\text {st }}$ century as one of the main models of science education. Many EU-funded projects have and are exploring the use of enquiry in teaching science following the Rocard Report (European Commission, 2007) and TEMI is one such project. One of the four innovations on which TEMI is based is the use of enquiry and the 5E model, with particular emphasis on the Engagement phase. In the 1980s the Biological Sciences Curriculum Study (BSCS) (http://www.bscs.org/) adopted the 5E model of enquiry and its origins and effectiveness were described in 2006 (Bybee et al, 2006). The 5E model is only one of a number of models of enquiry but it has been widely adopted and underpins the TEMI project. The 5E model is

\footnotetext{
${ }^{2}$ Please see appendix 2
} 
a learning cycle with five elements: it may be seen as a continuous cycle (Figure 1a) or one where the $5^{\text {th }}$ stage, Evaluation, feeds into to the other four throughout, instead of just at the end (Figure 1b).

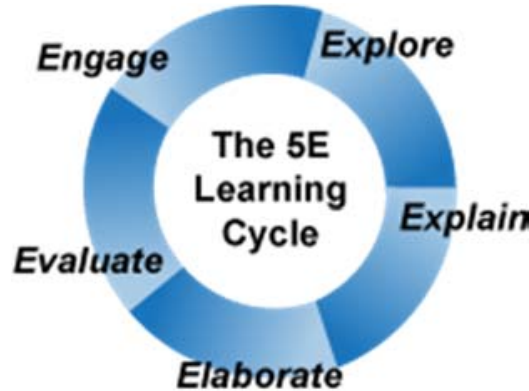

(a)

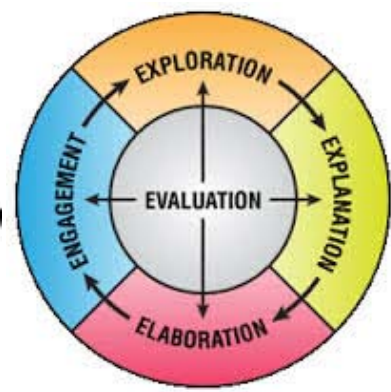

(b)

Figure 1 Two versions of the 5E learning cycle model

Sources: (a) http:// ergopedia.com/ ergoweb/home_chemistry.php (b)

https:/ / www.teachingchannel.org/ blog/ ausl/2014/ 03/ 16/ translating-ngss-into-classroominstruction-5e-planning-tool-and-teaching-tips/)

The model starts with the Engagement phase and moves through the others in sequence, with the cycle starting again with a new topic. While TEMI is interested in all five stages of inquiry, particular emphasis is placed on using mysteries to engage students in scientific concepts, so as to involve them in active inquiry. (Please see appendix two for more details on the $5 \mathrm{E}$ model.)

Each TEMI partner (listed in Appendix 1) has freedom to implement the project within their own educational and curricula framework. The authors, who all work in teacher education, decided to work directly with pre-service (PSST's) as well as with in-service science teachers (ISST's). Change in educational systems is always a complex and slow process. Consequently the authors felt it was important to start working with PSSTs as well as ISSTs, in order to equip the next generation of science teachers with new ideas and methods. The authors will now explore three specific dimensions of the TEMI project within their institution. These relate specifically to the involvement of PSST's in TEMI and include the pre-service science teacher as researcher, as part of a professional learning communities and as a collaborator with practicing teachers.

\section{TEMI and the pre-service science teacher as researcher}

Many teacher education programmes have historically failed to prepare teachers to conduct research into their practice (Henson, 1996). Trant (1998) stresses the importance of teachers engaging in action research (AR) as part of their professional roles. Such research may take the form of enquiry, reflection and action. Being supported to conduct and participate in research may encourage pre-service teachers to view research as central to the role and responsibility of the professional teacher (Rock \& Levin, 2002).

$\mathrm{AR}$ is a process of practitioner-directed enquiry into classroom practice, and is widely regarded as a compelling vehicle for helping teachers to improve their teaching and 
strengthen pupils' learning (Cochran-Smith \& Lytle, 1993). Although multiple models of AR have been articulated, most possess the same core elements (Goodnough, 2011). The process begins with the identification of a concern and an investigation into the causes of that concern. The practitioner then plans and implements a change designed to address the concern. Implementation of the change is carefully monitored, and data is collected and analyzed to understand the impact of the change (Lattimer, 2012). AR is therefore viewed as a cyclic process in which evaluations help the practitioner to understand what aspects of an intervention are responsible for the positive effects and what facets give rise to negative effects, so that changes in the innovation can be made (Hunter, 2007).

In addition to this, it should be noted that the recursive nature of AR places a high priority on reflection (Lattimer, 2012). Practitioners engaged in such forms of research must critically explore what they are doing, why they are doing it, and what impact has been made from it (Parsons \& Brown, 2002; Mertler, 2012). It is this type of reflection that has come to be seen as an integral part of professional practice. It encompasses the many ways in which professionals step back from their practice in order to contemplate, understand, and improve it (Hewson et al., 1999). With these goals in mind, AR is increasingly being adopted by pre service teacher education programmes (Carboni, Wynn, \&McGuire, 2002; Zambo \&Zambo, 2007).

Research into the impact of AR in pre-service teacher education indicates that pre-service teachers can benefit significantly from engaging in the process of enquiry and reflection that AR demands (Cochran-Smith, 2003; Schulz \& Mandzuk, 2005). Traditionally, teacher education has relied upon an apprenticeship model within which novices replicate the model provided by the experienced master teacher (Kitchen \& Stevens, 2008). By introducing AR to pre-service teachers, they can adjust their views of what it means to be a teacher and it also encourages them to "develop a distinctive [teaching] approach based on evidence of student learning" (Kitchen \&Stevens, 2008, p. 44). By going through the processes of AR, pre-service teachers can begin to realise that they are capable of transforming pupil learning by researching their own practice, and their conceptual understanding of teaching and learning changes (Kitchen \& Stevens, 2008). A voluminous literature representing work in several countries reinforces these findings. It has been consistently reported for example, that teachers (pre-service and in-service) who engage in AR, generally become more aware of their own practices; of the gaps between their beliefs and practices; and of what their students are thinking, feeling, and learning (Elliott, 1980; Biott, 1983; Ruddick, 1985; Noffke \& Zeichner, 1987).

In the University of Limerick, action research is introduced to undergraduate pre-service teachers in their final year of study (year four), where they are required to complete an academic research project. These pre-service teachers research a topic in depth of their own choosing, over a period of 10 months (end of third year to middle of fourth year). Many choose to complete this project using AR. This type of a research activity allows the pre- 
service teachers to become creators of knowledge, rather than mere consumers of it (Noffke \& Stevenson, 1995).

However, it must also be acknowledged that against these positive findings, previous research also noted limitations of AR in pre-service teacher education. Subramaniam (2010) cautioned that the context within which it takes place can significantly shape pre-service teachers' perceptions of the work. The novice status of the pre-service teacher may also necessarily limit the potential learning that can be derived from participation in AR (Price, 2001). For this reason, prospective teachers in UL are guided by academic supervisors throughout their projects.

Four final year pre-service science teachers (PSSTs) participated in AR within the first phase of the TEMI project (2013-14) in UL. These PSSTs initially identified the need to introduce more inquiry-based teaching and learning approaches into science classrooms in Ireland, to engage pupils in science, and to move away from the prevailing direct transmission approaches. Three of the PSSTs focused their project on enquiry in the physics, chemistry and biology domains of lower second level science respectively. The fourth PSST focused their attention on the challenges of engaging students in Transition $\mathrm{Year}^{3}$. All four of the PSSTs planned an intervention strategy, involving the development of Inquiry Based Science Education (IBSE) classroom materials based on mysteries/discrepant events, the trialling of these materials and finally the evaluation of these materials for their effectiveness in engaging and motivating pupils in science through inquiry. The PSSTs trialled their intervention resources over the course of their final 10-week school placement (Autumn, 2013) and evaluated these based on students' feedback (via questionnaires).

\section{TEMI and the development of Professional Learning Communities}

For curriculum initiatives to be effective it is imperative that the beliefs and values of those responsible for implementing reforms are altered (Fullan, 2013). The embrace of change can only truly take place once an inner change has occurred to a person's beliefs and values (Sheehy, 1981). Goodson (2001), highlighting the importance of the personal dimension of change, stresses that personal change must be deemed as central to the change process. Alterations to one's beliefs and values are more likely to occur when change has been introduced via a partnership model (Trant, 1998, p. 7). Within such an approach theinternal (e.g. in-service or pre-service teachers) and external players (e.g. teacher education providers) are "integrated and harmonized" (Goodson, 2001, p.46). The adoption of such an inclusive approach, wherein teachers work with external agencies (such as teacher education providers) responsible for change, ensures an effective and sustainable approach to curriculum change. A Professional Learning Community (PLC) is one such vehicle for attempting to promote collaboration and integration between teachers and external agencies (J ones, Gardner, Robertson \& Robert, 2013).

\footnotetext{
${ }^{3}$ Transition Year is an optional year between the junior and senior secondary cycles in Ireland, which is not examined and has no set curriculum, allowing teachers an opportunity to innovate.
} 
The traditional workshop model for professional development has evolved in recent years with the establishment of meaningful collaboration through learning communities, in the form of support systems and classroom application (Lumpe, 2007). In recent decades, professional learning has moved away from the traditional in-service mode (stand-alone workshops) toward long-term, continuous learning. In traditional stand-alone professional development courses, teachers can often feel isolated despite having a productive and positive experience at a one-day workshop. If teacher learning takes place within the context of a professional community, which is nurtured and developed from both inside and outside school, the effects may be not only an expanded conception of teacher development, but the accomplishment of significant and lasting school change (Lieberman, 1995).

There are five common characteristics of a PLC (J ones et al., 2013; Nelson, 2009):

1. Building the foundation on teachers' shared values and vision.

2. Promoting collective responsibility for student learning.

3. Increasing reflective professional inquiry.

4. Promoting collaboration.

5. Integrating collective and individual learning.

The move towards greater integration of action research in teacher education programmes, as described earlier, is student-centred. The establishment of PLCs is also a move towards a more constructivist-orientated approach (Nelson, 2009). Jones, Garner, Robertson and Robert, (2013) describe a PLC as a suitable "vehicle" for engaging both schools and teachers in examining professional practice and implementing reform-based change in the classroom.

PLCs are popular in the USA and are now slowly growing in popularity in Europe and Ireland. A Green Paper on Teacher Education in Europe (2000) highlighted the need for teachers to have the ability to develop professional autonomy and to become pro-active agents of change (Buchberger, Campos, Kallos, \& Stephenson, 2000). The implementation of the TEMI project in Ireland provides a unique opportunity for in-service and pre-service teachers to collaborate on their professional development as part of a PLC.

PLCs vary depending on school systems, teachers and the goals of the PLC. The PLC that was established in the TEMI project involved the collaboration of three different groups of professionals (not just in-service teachers as is the case in many other professional learning communities). There were three groups involved in the TEMI project: the PSSTs, the ISSTs and the Science Education/Teacher Education Researchers. Each partner had a key role in the TEMI PLC (Figure 2). 
Pre-service science teachers

-Development, trial and evaluation of TEMI resources

-Facilitation of TEMI idea development in the workshops

-Support for in-service science teachers sourcing ideas, resources

-Analysis and feedback on the effectiveness of TEMI lessons in the classroom
In-service science teachers

-Sharing personal classroom experience -Insightful understanding of second-level pupils' ability, interests etc. -Realistic expectation for development and implementation of TEMI within current second level environment
Science Education

Researchers

-Recruitment and coordination of participants - Organisation of the two full day workshops -Setting up the online Google COmmunity for a virtual Professional Learning Community - Facilitating discussion and communication within the Professional Learning Community

Figure 2. Participants in the TEMI Professional Learning Community

As part of the TEMI project, the pre-service and in-service teachers met together for two full one-day workshops in UL. There were 12 weeks between the two workshops. Attempts were made to begin the establishment of a PLC at the first face-to-face workshop meeting. In this meeting, the PSSTs shared their experiences of sourcing ideas, developing, trialling and evaluating TEMI lessons. Prior to this meeting the ISSTs had received a sample of materials developed by the PSSTs. A number of the ISSTs trialled or read through these materials.

As part of their Final Year Projects, the PSSTs were involved in an AR project, as previously discussed, where they developed, trialled and evaluated TEMI teaching resources while on their final school teaching placement (Autumn 2013). Based on their experience, the PSSTs assumed the role of facilitators in the first workshop. Each PSST worked individually with ISSTs to facilitate their initial development of TEMI lesson ideas, as they had experience of sourcing mysteries and discrepant events for the "engage" part of the TEMI lessons, which the ISSTs had not. The PSSTs' experience of implementing the TEMI lessons also meant that they could share their insights into the challenges of implementing the ideas e.g. the need to scaffold the pupils in moving from the engage to the explore phase. In the second workshop day, thePSSTs and ISSTs each shared their classroom experiences and gave feedback on the effectiveness of different innovations of the TEMI project and the particular lessons.

The PLC was set up in the TEMI project with the aim of developing meaningful and sustained collaboration (Lumpe, 2007). To facilitate the communication in the PLC, the TEMI project team in UL set up an online forum. Google ${ }^{\text {Tm }}$ was used as a platform for this forum. All participants had access to a shared TEMI Folder in Google Drive ${ }^{\mathrm{TM}}$. All participants joined the private TEMI Google Community ${ }^{\mathrm{Tm}}$. The TEMI Google Drive ${ }^{\mathrm{Tm}}$ folder contained all of the TEMI resources that were developed and trialled by the PSSTs. The folder also 
contained relevant literature about the 5-E model of IBSE (described above) as well as relevant online books and sources for scientific mysteries and discrepant events.

In between the two workshop days, the three participating groups remained in contact through an online Google ${ }^{\mathrm{Tm}}$ forum. The Google Drive ${ }^{\mathrm{Tm}}$ folder was used to share the developed resources. The Google Community ${ }^{\mathrm{Tm}}$ was useful to host on-going conversations and discussions between the members of the PLC relating to:

- Feedback on trialled lessons.

- Sourcing of lesson ideas.

- Links to useful websites and resources.

- Discussion about sourcing resources and materials.

- Reflections and suggestions about aspects of lessons that were trialled.

This online discussion forum became a place for professional support and community (Nicholson \& Bond, 2003). The use of the platform in-between both workshops aided the development of a sense of community among PSSTs and ISSTs in cyberspace. As the online community evolves and matures, the participants can grow closer to each other, developing a strong sense of camaraderie (ibid, 2003). This TEMI Google Community will grow throughout the 42 month TEMI project in the number of participants in the professional community, as the number of teachers (ISSTs and PSSTs) involved in the TEMI project grows in successive cohorts.

This group of PSSTs $(n=4)$ and ISSTs $(n=5)$ in the first TEMI cohort have now finished their formal involvement in professional development as part of the TEMI project. Previous research has highlighted that such a limited amount of time may be insufficient to develop the relationships and habits that typify a community (Nicholson \& Bond, 2003). However, these teachers will remain as members of the online forum in order to extend their participation in the PLC beyond the individual two, one-day workshops. The authors acknowledge that the participants were required to participate in the online discussion as part of their involvement in the TEMI project. The UL Team provided regular reminders and prompts for discussion on the forum. However, the active involvement of the participants in this exploratory study is an encouraging beginning for similar collaborations and development of communities in the future. As well as engaging in the professional learning community, the PSSTs also had the opportunity to work closely with another group of ISSTs during their school placement, namely their cooperating science teachers (CSTs).

\section{TEMI and pre-service teachers' collaboration with co-operating science teachers}

Enabling teachers to work together in a collaborative manner, where they are provided with opportunities to "discuss their beliefs about teaching and learning with one another, critique their own practice, systematically test new ideas, and share their findings with one another" (Windschitl, 2002, p. 161), is viewed as an effective approach to teacher development. Furthermore, providing opportunities for experienced and in-experienced teachers to work 
together has been stressed as an effective approach to teacher development. Cochran-Smith (1991) states that "the only way for beginners to learn to be both educators and activists is to struggle over time in the company of experienced teachers who are themselves committed to collaboration and reform in their own classrooms" (p. 307). Such forms of collaboration have the potential to bring about meaningful learning and professional development for both experienced and in-experienced teachers (ibid, 1991).

It is common knowledge that in-service teachers play a unique role within the education system in providing for the holistic development of pupils within their classes. However, they also have a significant role to play with pre-service teachers during their initial teacher education programmes, especially at a time when teacher education programmes have extended school placement periods to help prepare future teachers for the demands of teaching (Teaching Council, 2011). The period of school placement not only provides preservice teachers with an opportunity to be involved in classroom teaching but it is also a time where they can apply educational theory in a variety of teaching situations and contexts, while also getting involved in non-teaching activities such as supervision and attending staff meetings (ibid, 2011). During this time however, pre-service teachers must overcome several hurdles, including juggling the responsibilities of teaching while at the same time establishing and maintaining positive relationships with their co-operating teachers and other school personnel. Significant research has been carried out on the relationships preservice teachers develop with their cooperating teachers, including the cooperating teachers' roles and functions during school placement. The possible roles that can be developed are outlined by $\mathrm{Lu}$ (2013), where she described three roles: that of a co-operating teacher, a mentor teacher and a supervising teacher.

All teachers, including PSSTs, must complete certain tasks during their normal school day. Reynolds (1992) labels and separates these teaching tasks into the domains of pre-active, interactive, post-active and administration tasks, which together provide opportunities for understanding to take place in the school setting. Figure 3 represents the operations that are involved in each task. 


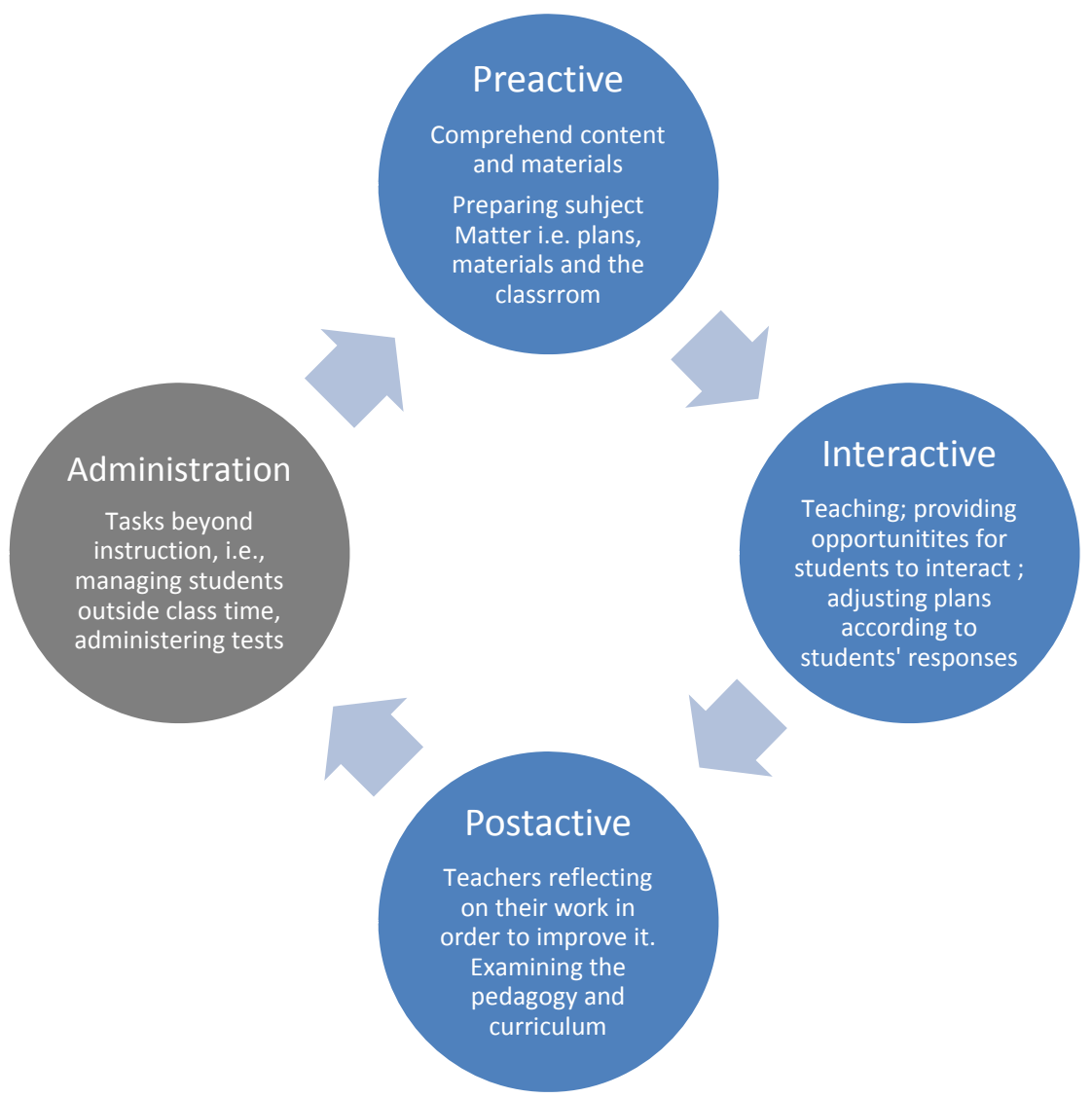

Figure 3: Domains of teacher tasks (Reynolds, 1992)

As figure 3 shows, Reynolds identifies four distinct tasks for teachers. The pre-active domain occurs before the teachers (in our case PSSTs) come in contact with the pupils and can be identified as lesson planning. The interactive domains consists of the pedagogical application during the teaching of the content and the post-active domain involves the activities teachers do to improve their teaching i.e. gathering and analysing data on the ability of their students, reflecting on pedagogical approaches and engaging in continuous professional development. If PSSTs are to be effective teachers during their school placement they must receive support and direction on how to correctly achieve the outcomes of all four domains. As well as preparing engaging lessons, PSSTs also need support with delivering the planned lesson, ensuring all elements of the instructional design - learning activities, materials and teaching strategies - are appropriate to both the content and the student ability. The PSST must then reflect on the success of the lesson and use their experience to positively impact on future lessons. PSSTs do not have a great deal of teaching experience prior to the placement and rarely observe the post-active activities outlined above, although they are critical to preserving and enhancing the profession (Baird, Fensham, Gunstone \&White, 1991). To this end the pre-service teachers need guidance and support from their co-operating teachers during their school placement to help them develop as effective teachers. There is much research available on the pre-service teachers' relationship and interaction with co-operating teachers during the interactive stage of teaching (Clarke, Triggs \& Nielson, 2014; Lum, 2013; Caires \& Almeida, 2007). However, the research is limited when looking at pre-service 
teachers' interaction with co-operating teachers during the pre-active and post-active tasks of teaching.

The TEMI project provided an opportunity for PSSTs and their respective cooperating science teachers (CSTs) to work together during school placement at both the pre-active and post-active tasks of teaching. Their involvement in the TEMI project also provided the PSSTs with an opportunity to work with their CSTs, where they were able to share their learning of IBSE and introduce the new ideas and approaches into their placement school. This led to wider dissemination of the TEMI approach and resources as the 4 PSSTs were all placed in different schools for their school placement experience. Similarly to thePLC, the PSSTs could learn from their CSTs, and the CSTs were exposed to TEMI lessons from the PSSTs. The approach also sought to begin the discussion in schools on the use of IBSE, in particular the use of mysteries/ discrepant events in teaching science, as a possible pedagogical approach that can support the reform currently taking place in Irish curriculum. This introduction to the TEMI project also resulted in some teachers and schools being recruited for the project.

\section{Concluding thoughts - potential benefits of involving PSST's in TEMI}

The TEMI project team at the University of Limerick has benefitted due to the involvement of PSSTs. Firstly, the students developed and trialled a variety of mysteries before and during their school placement, which helped to provide initial teaching resources for the first cohort of ISSTs. The PSSTs also disseminated the work further through their engagement with their CSTs and pupils while on school placement. This may have provided greater awareness of the project within schools. Community awareness and support are fundamental to the successful implementation of change in classrooms (Hanson, 2001). The PSSTs also provided a different perspective and voice to the ISSTs during the workshops, and were able to share their experience in sourcing, developing and trialing materials.

The involvement of PSSTs may have had additional benefits beyond this. Sociocultural theory argues that we learn from our more capable peers (Vygotsky, 1978). Therefore, involving both pre-service and in-service teachers should be a mutually beneficial process. Edens (2000), for example, highlights the many benefits of a shared space for reflection for PSSTs, whereby through reflecting together, PSSTs take their knowledge to the next level of analysing, applying, evaluating, and synthesizing information shared in class during their practice. In relation to both the PLC and collaboration with co-operating teachers, PSSTs were provided with an opportunity to learn from the more experienced ISSTs but also the ISSTs could learn about the development of the TEMI lessons from the PSSTs. This was particularly evident in the face-to-face workshops and through the discussion on the online forum. Engaging PSSTs in action research (AR) may have supported these students in developing an understanding of the importance of the teacher as researcher and an appreciation of the merits of researching one's own practice (Trant, 1998). Engaging in such a process may hopefully result in more reflective teachers who are more open to responding 
to changes in their environment and to their pupils' needs (Kitchen \& Stevens, 2008). The ideal is that these PSSTs at least won't merely conform to the dominant teaching and learning approaches most evident in Irish post-primary schools but rather that they would begin to realise that through engagement in AR, they can make a difference to their pupils' experiences of science.

This paper has explored the potential mutual benefits of involving PSSTs in continuing professional development with ISSTs and with the project team. TEMI is a 42 month project which will involve providing teacher development to five more cohorts of ISSTs in the remainder of the project. The authors hope that sharing the experiences of the PSSTs with the first TEMI training cohort will establish a foundation for future collaborative professional development of PSSTs and ISSTs in the TEMI project. This discussion paper has explored the potential benefits of involving pre-service and in-service teachers in collaborative professional development, which extends beyond the scope of the TEMI project, to the broader professional development in other disciplines. A second group of PSSTs (5 in number) has been involved in the second phase of the TEMI project (2014-15), which is still on-going.

\section{Acknowledgements}

This work was supported by the European Commission under the FP7-Science-in-Society2012-1, Grant Agreement N. 321403 


\section{References}

Baird, J .R., Fensham, P.J ., Gunstone, R.F. and White, R.T. (1991). The Importance of Reflection in Improving Science Teaching and Learning. J ournal of Research in Science Teaching, 28(2), 163-182.

Biott, C. (1983). The foundations of classroom action research in initial teacher training. J ournal of Education for Teaching, 9, 152- 160.

Bybee, R. W., Taylor, J . A., Gardner, A., Van Scotter, P., Carlson Powell, J., Westbrook, A. and Landes, N. (2006). The BSCS 5E Instructional Model: Origins and Effectiveness, Colorado Springs, CO: BSCS.

Buchberger, F., Campos, B. P., Kallos, D., \& Stephenson, J. (2000). Green Paper on Teacher Education in Europe: High Quality Teacher Education for High Quality Education and Training. Sweden: Thematic Network on Teacher Education in Europe.

Cairnes, S., \&Almeida, L. S. (2007). Positive aspects of the teacher training supervision: The student teachers' perspective. European J ournal of Psychology of Education, 22(4), pp. 515-528.

Callan, J . (1995). Equality of learning in quality schooling: a challenge for curriculum implementation in Issues and strategies in the implementation of educational policy, Coolahan, J. (ed.). Maynooth: Education Department.

Carboni, L. W., Wynn, S., \& McGuire, C. (2002). Action research with undergraduate pre-service teachers: Emerging and merging voices. Action in Teacher Education, 29(3), 50- 59.

Clarke, A., Triggs, V., \& Nielson, W. (2014). Cooperating Teacher Participation in Teacher

Education: A Review of the Literature. Review of Educational Research, 84(2), 163-202.

Cochran-Smith, M. (2003). Learning and unlearning: The education of teacher educators. Teaching and teacher education, 19(1), 5-28.

Cochran-Smith, M., \& Lytle, S. (1993). Inside/ outside: Teacher research and knowledge. New York: Teachers College Press.

Department of Education and Skills (2012). A framework for J unior cycle, Dublin: Stationery Office.

Edens, K. M. (2000). Promoting communication, inquiry and reflection in an early practicum experience via an on-line discussion group. Action in Teacher Education, 22(2A), 14-23.

Elliott, J . (1980). Implications of classroom research for professional development. In, Professional development of teachers. E. Hoyle \&J . Megarry (Eds.) London: Kogan Page.

European Commission. (2007). Science Education Now: A Renewed Pedagogy for the Futuee of Europe. Brussels: European Commission [online] available:http://ec.europa.eu/research/sciencesociety/document_library/pdf_06/report-rocard-on-science-education_en.pdf [Accessed 28/7/ 15]

Fullan, M. (2013). The new meaning of educational change, London: Cassell.

Gleeson, J . (2010). Curriculum in context: Partnership, power and Praxis in Ireland. Peter Lang: Oxford.

Goodnough, K. (2011). Examining the long-term impact of collaborative action research on teacher identity and practice: The perceptions of K- 12 teachers. Educational Action Research, 19(1), 7386.

Goodson, I. (2001). 'Social Histories of Educational Change', J ournal of Educational Change, 2, 4563.

Government of Ireland (1998). Commission on the points system, Dublin: Stationery Office.

Henson, K. T. (1996). Teachers as researchers. Handbook of research on teacher education, 2, 53-64.

Hewson, P. W., Tabachnick, B. R., Zeichner, K. M., Blomker, K., Meyer, H., Lemberger, J., Marion, R., Park, H., \& Toolin, R. (1999). Educating prospective teachers of biology: Introduction and research methods. Science Education, 83, 247- 273. 
Hunter, W. J . F. (2007). Action research as a framework for science education research, in Bodner, G. M. and Orgill, M., Theoretical Frameworks for Research in Chemistry/ Science Education. Upper Saddle River, NJ : Pearson Prentice Hall.

J ones, M. G., Gardner, G. E., Robertson, L., \& Robert, S. (2013). Science Professional Learning Communities: Beyond a singular view of teacher professional development. International J ournal of Science Education, 35(10), 1756-1774.

Kitchen, J ., \& Stevens, D. (2008). Action research in teacher education: Two teacher-educators practice action research as they introduce action research to preservice teachers. Action Research, 6(1), 7- 28.

Lattimer, H. (2012). Action research in pre-service teacher education: Is there value added? Inquiry in Education, 3(1).

Lieberman, A. (1995). Practices that Support Teacher Development: Transforming Conceptions of Professional Learning Innovating and Evaluating Science Education: NSF Evaluation Forums, 1992-94 (pp. 67-78). Washington: National Science Foundation: Directorate for Education and Human Support.

Liem, T.L. (1990). Invitations to Science Inquiry, 2nd. Ed. Chino Hills, CA: Science Inquiry Enterprise

Lu, H. (2013). Pre-service Teachers' Issues in the Relationship with Cooperating Teachers and Their Resolutions. US-China Education Review B, 3 (1), 18-28

Lumpe, A. T. (2007). Research-Based Professional Development: Teacher engaged in Professional Learning Communities. J ournal of Science Teacher Education, 18, 125-128.

McCormack, A.J . (1990). Magic and Showmanship for Teachers. Riverview, FL: Idea Factory

McCormack, O. and O'Flaherty, J . (2010). An examination of pre-service teachers' attitudes towards the inclusion of development education into Irish post-primary schools, Teaching and teacher education, Vol. 26, (6), 1332-1339.

Mertler, C. (2012). Action research: Improving schools and empowering educators (3rd ed.) Thousand Oaks, CA: Sage.

Nelson, T. H. (2009). Teachers' collaborative inquiry and professional growth: Should we be optimisic. Science Teacher Education, 93(3), 548-580.

Nicholson, S. A., \& Bond, N. (2003). Collaborative Reflection and Professional Community Building: An Analysis of Preservice Teachers' Use of an Electronic Discussion Board. J ournal of Technology and Teacher Education, 11(2), 259-279.

National Council for Curriculum and Assessment (2011). Towards a framework for junior cycle, Dublin:NCCA.

National Council for Curriculum and Assessment (2013). Background Paper and Brief for the Review of J unior Cycle Science, Dublin: NCCA.

Noffke, S. E., \& Stevenson, R. B. (1995). Educational action research: Becoming practically critical. New York: Columbia Teachers College Press.

Noffke, S., \&Zeichner, K. (1987). Action research and teacher development. Paper presented at the annual meeting of the American Educational Research Association, Washington, DC.

O’Brien, T. (2010). Brain-powered science: Teaching and learning with Discrepant Events. Arlington, VA: NSTA Press

Organisation for Econonomic Co-operation and Development (1991). Ireland. Reviews of national policies for education, Paris: OECD.

Organisation for Economic Co-operation and Development (2009). Teaching and learning international study, Paris: OECD.

Osborne, J ., \& Dillon, J . (2008). Science Education in Europe: Critical Reflections A report to the Nuffield Foundation. London: King's College.

Parsons, R. D., \& Brown, K. S. (2002). Teacher as reflective practitioner and action researcher. Belmont, CA: Wadsworth/Thompson Learning. 
Price, J . N. (2001). Action research, pedagogy, and change: The transformative potential of action research in pre-service teacher education. J ournal of Curriculum Studies, 33(1), 43- 74.

Reynolds, A. (1992). The Knowledge Base for Beginning Teachers: Education Professionals' Expectations versus Research Findings on Learning to Teach. The Elementary School J ournal, 95(3) 199-221.

Rock, T. C., \& Levin, B. B. (2002). Collaborative action research projects: Enhancing preservice teacher development in professional development schools. Teacher Education Quarterly, 7-21.

Ruddick, J . (1985). Teacher research and research-based teacher education. J ournal of Education for Teaching, 11, 281-289.

Schulz, R., \& Mandzuk, D. (2005). Learning to teach, learning to inquire: A 3-year study of teacher candidates' experiences. Teaching and Teacher Education, 21(3), 315- 331.

Sheehy, G. (1981) Path Finders: How to Achieve Happiness by Conquering Life's Crises, London: Sidgwick \&J ackson.

Subramaniam, K. (2010). Images in action: Preservice teachers' action researcher images. Qualitative Report, 15(3).

Teaching Council (2011). Initial Teacher Education: Criteria and Guidelines for Programme Providers. Dublin, Ireland: Teaching Council

TEMI (2013), What is a mystery?'[online] available: http://teachingmysteries.eu/en/resources/ [accessed 28 J uly 2015].

Trant, A. (1998). Giving the curriculum back to teachers: Curriculum development and the teacher's role, The future of the curriculum, Dublin, VED: Curriculum Development Unit.

Vygotsky, L. (1978). Mind in Society: The development of higher psychological processes. Cambridge, MA: Harvard University Press.

Windschitl, M. (2002). Framing constructivism in practice as the negotiation of dilemmas: An analysis of the conceptual, pedagogical, cultural and political challenges facing teachers. Review of Educational Research, 72(2), 131- 175.

Zambo, D., \&Zambo, R. (2007). Action research in an undergraduate teacher education program: What promise does it hold? Action in Teacher Education, 28(4), 62- S74.

\section{Appendix 1}

Table 1. Consortium of the TEMI project

\begin{tabular}{l}
\hline TEMI Partners \\
\hline Queen Mary, University of London - UK \\
Università degli Studi di Milano - Italy \\
Bremen University - Germany \\
University of Limerick - Ireland \\
Sheffield Hallam University - UK \\
Hogskolen I Vestfold - Norway \\
University of Vienna - Austria \\
Weizmann Institute - Israel \\
Leiden University - Netherlands \\
Charles University Prague - Czech Republic \\
Sterrenlab - Netherlands \\
TRACES - France \\
Cnotinfor - Portugal \\
\hline
\end{tabular}




\section{Appendix 2}

Summary of the BSCS 5E Instructional Model (Bybee et al, 2006)

\section{Engagement}

The teacher or a curriculum task accesses the learners' prior knowledge and helps them become engaged in a new concept through the use of short activities that promote curiosity and elicit prior knowledge. The activity should make connections between past and present learning experiences, expose prior conceptions, and organize students' thinking toward the learning outcomes of current activities.

\section{Exploration}

Exploration experiences provide students with a common base of activities within which current concepts (i.e., misconceptions), processes, and skills are identified and conceptual change is facilitated. Learners may complete lab activities that help them use prior knowledge to generate new ideas, explore questions and possibilities, and design and conduct a preliminary investigation.

\section{Explanation}

The explanation phase focuses students' attention on a particular aspect of their engagement and exploration experiences and provides opportunities to demonstrate their conceptual understanding, process skills, or behaviours. This phase also provides opportunities for teachers to directly introduce a concept, process, or skill. Learners explain their understanding of the concept. An explanation from the teacher or the curriculum may guide them toward a deeper understanding, which is a critical part of this phase.

\section{Elaboration}

Teachers challenge and extend students' conceptual understanding and skills. Through new experiences, the students develop deeper and broader understanding, more information, and adequate skills. Students apply their understanding of the concept by conducting additional activities.

\footnotetext{
Evaluation

The evaluation phase encourages students to assess their understanding and abilities and provides opportunities for teachers to evaluate student progress toward achieving the educational objectives.
} 